\title{
Analysis of workplace injuries in Slovakian state forestry enterprises
}

https://doi.org/10.1515/eng-2019-0049

Received February 12, 2019; accepted April 8, 2019

\begin{abstract}
The aim of the paper is to identify the most common workplace accidents regarding injured body parts with respect to anthropometric data measurements of the population in the Slovak republic. Data from workplace accidents database over the years 2000-2017 were drawn from the records of the Slovak Forest state enterprise. The highest number of workplace accidents $(31.7 \%$ of all recorded workplace accidents) occurred during the forest harvesting phase. Timber skidding with $15.9 \%$ of recorded accidents was the second highest risky phase. In four phases Timber harvesting, timber skidding, Works at conversion depot, Repairs and maintenance was $76 \%$ from all injuries in forestry state enterprises was occurred. Nonsignificant increase in the injury rate over the years 20002017 was determined in the analysis of the injury rate in the Slovak state forests. From the point of view of the longterm changing anthropometric parameters of the adult population, it is also necessary to take into account the ergonomic parameters and the technological procedures of the performed work and the working environment.
\end{abstract}

Keywords: injury, body parts, work safety, forestry operations

\section{Introduction}

Forestry sector in Slovakia is, in terms of output on gross domestic product, among the less important economic sectors. Its extraordinary importance, however, is in the fulfillment of all-community and environmental functions, as the forest cover of the Slovak Republic is about

\footnotetext{
^Corresponding Author: Miloš Gejdoš: Department of Forest Harvesting, Logistics and Ameliorations; Technical University in Zvolen, Faculty of Forestry; Zvolen; 960 53; Slovakia, E-mail: gejdos@tuzvo.sk

Mária Vlčková: Department of Forest Harvesting, Logistics and Ameliorations; Technical University in Zvolen, Faculty of Forestry; Zvolen; 960 53; Slovakia
}

$41 \%$ (more than half are managed by state forestry enterprises) [1]. Ensuring these functions requires the implementation of the whole complex of work activities, which culminate in the final phase with the timber harvesting and its evaluation. The whole economy of forestry enterprises is virtually dependent on this activity. These works are demanding for physical abilities, professional experience, application of prescribed work operations and are extremely risky in terms of threats to human health and life. They therefore require qualified and educated workers, who carry out these works. Managing human potential in this area is thus linked to the level of education, motivation, but also corporate culture and ways of providing these services [2-7]. With the onset of powerful multioperation technologies for forest works, some of the risks have been minimized, but others have arisen in the area of neuropsychic burden and need for an even more skilled workforce. In Slovakian conditions, for a number of reasons, there is no possibility the massive deployment of these technologies, and motomanual technology is dominated by the use of hand-held chain saws. At present, the personal problem of the lack of sufficiently skilled workers is starting to reflect, that they would be willing to carry out this difficult and risky job at the current wages. The trend in forestry enterprises is to outsource these works, transferring a large part of the tax burden to self-employed workers, while minimizing the risks. The aim of this article is to analyze the occurrence of work accidents during the last seventeen years in conditions of state forestry entities of the Slovak Republic. We focused on the risk assessment of individual working phases as well as the frequency of injury to individual parts of the body.

\section{Methodology}

Data associated with workplace injuries were drawn from the records of the state enterprise Forests of the Slovak Republic seated in Banská Bystrica. Gathered data were processed and entered into the database complemented by the data on injuries of the self-employed working in forest industry. Workplace accidents were identified with ac- 
cordance with "European Statistics on Accidents at Work" (ESAW) [8] in order to create a dataset. Circumstances and causes of workplace accidents in Slovakia were determined using the authors' classification based on the Decree of Ministry of Labour, Social Affairs and Family of the Slovak Republic No. 500/2006 Coll. on establishment of a template for reported occupational accident in accordance with the unified statistical reporting system in the European Union [9]. A dataset of workplace accidents was created over the years 2000-2017. During the analysis period, 2041 workplace accidents in forest enterprises in Slovakia were recorded.

A method of contingency tables was used to analyse the correlation between qualitative (categorical) variables in a dataset consisting of workplace injuries.

Investigation of the correlation between two variables is based, similarly to one-dimensional statistical dataset, on finding frequencies mentioned in contingency tables. Research methodology follows the works [10-13].

The aim of the injury rate analysis is to make decision about the effect of the commonly used prognostic variables on the injury rate. Moreover, the association between the prognostic variables and injury rate is studied as well [14]. The analysis is carried out using the Poisson regression model. The model is often used to analyse the data related to age group in epidemiology [15-18] and it is mentioned in several works $[14,19,20]$.

Statistical models provide a possible solution to the problem. Poisson regression models provide a standard framework for more complex statistical analyses of injury rate. However, a detailed insight into the impacts of many variables is possible as well. Injury rate is estimated with regard to the number of accidents $(d)$ divided by the amount of produced wood $\left[1000 \mathrm{~m}^{3}\right](N)$,

$$
\text { Injury rate } \left.=d / N \text {, [Nr. of Accidents } / 1,000 \mathrm{~m}^{3}\right]
$$

Data associated with wood production over the previous years were drawn from the Green report issued by the Ministry of Agriculture and Rural Development of the Slovak Republic [21].

The number of injuries is predicted using the Poisson distribution with the mean $\mu_{d}=N{ }^{\star} \lambda$, where $\lambda$ is the incident injury rate. The average number of injuries, injury rate is expressed by parametric function of prognostic variables. As the Poisson distribution assumes that, the meaning value in distribution is greater than zero, this function of prognostic variables is often limited by the values of a function are greater than zero. Following logarithmiclinear model is usually used to modeling the injury rate $\lambda$ as a function of a set of prognostic variables $X_{1}, \ldots \ldots . X_{p}$ :

$$
\log (\lambda)=\log \left(\mu_{d} / N\right)=\beta_{0}+\beta_{1} X_{1}+\ldots+\beta_{p} X_{p}
$$

or:

$$
\log \left(\mu_{d}\right)=\beta_{0}+\beta_{1} X_{1}+\ldots+\beta_{p} X_{p}+\log (N)
$$

where $\beta$ is a regression coefficient of average number of injuries of $i$-th prognostic variable $X(i=1 \ldots . . n)$. Thus, log (of rate) is a linear function of prognostic variables. In the language of generalised linear models (GLMs), the usual specification of the linear component due to the inclusion of the term $\log (N)$. This term is called the "offset" [22, 23]. In the $\log$ function (Formula $2 b$ ) the average number of injuries is expressed using the linear combination of prognostic variables while $\log (N)$ is expressed by fixed value coefficient. The analyses relate to the amount of produced wood. The number of employees (full-time as well as parttime workers) can be used as an alternative to the produced wood $\left[1000 \mathrm{~m}^{3}\right]$.

If the variance and the mean are equal, is the condition to select Poisson distribution for the number of injuries $(d)$ fulfilled. Multiple linear regression with homogeneity of variances is based on the Poisson distribution.

Many important things have to be taken into consideration when the models are used, for example, whether models are specified correctly - determination of prognostic variables or appropriate method for distribution. Additional analyses have to be carried out in order to determine the suitability of the regression model for making predictions. Moreover, the data quality must be evaluated (reliability, accuracy, etc...) as well as random factors related to the analyses of injury rate resulting from the various source of data.

\section{Results}

During the analysis period, 2041 workplace accidents in forest enterprises in Slovakia were recorded. 1991 injuries were reported in group of men and 50 in women. It is related to the type of forestry work. The sex ratio is 3: 1 for the group of men. Difficult and dangerous work is performed almost exclusively by men.

The most risky phase is timber harvesting (31.7\% of all recorded injuries). The second risky phase is timber skidding with $15.9 \%$ of all recorded workplace injuries (Fig. 1). Works at conversions depots (15.4\%) and Repairs and maintenance $(13.3 \%)$ can be also marked as a risky phases. In this four phases more than $76 \%$ (1556) of all injuries was marked. 
The number of injuries according to injured body parts in these four phases is on Figure 2. The most injured body part are legs. In this four phases is the share of injuries on the legs approximately $40 \%$. Within the phase "Repairs and maintenance" are the legs the most injured part of body. The second injured body part are arms ( $24.6 \%$ share). However, it should be noted that legs and arms injuries are generally not fatal in terms of endangering of the human life.

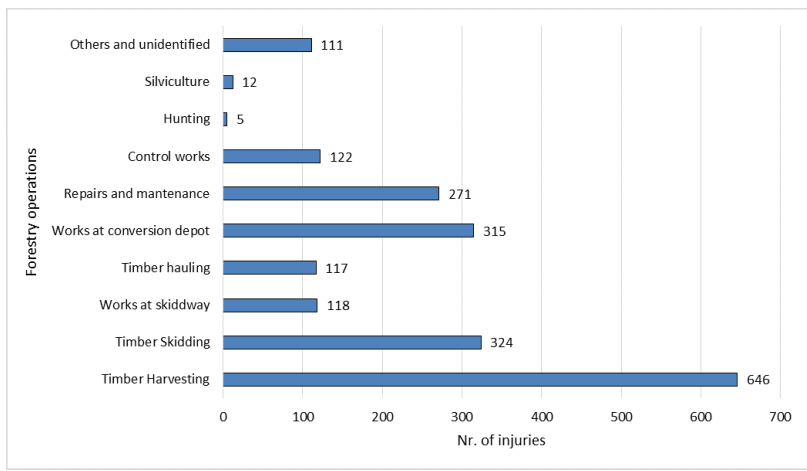

Figure 1: Workplace injuries in State forestry enterprise in the years 2000-2017

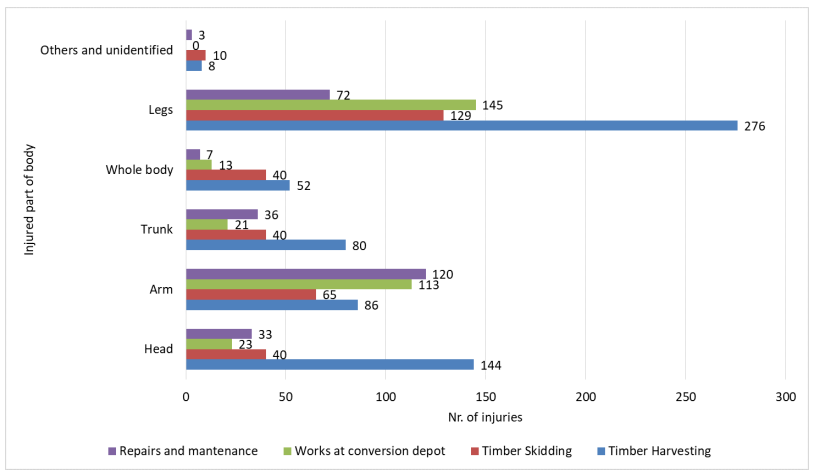

Figure 2: Workplace injuries according to injured body parts in State forestry enterprise (years 2000-2017)

In Table 1 are the injuries according to body part and days in the week. The highest number of injuries arises logically in Monday. The workers (after 2 days off) are not fully concentrated on the work. The lowest number of injuries during the "classically" work days was in Friday recorded. Serious and life-threatening injuries, mainly on Tuesdays and Wednesdays were occured. It was primarily about head and body injuries or multiple parts of the body.

Injury rate in the forest industry over the years 2000 2017 was decreasing. Trend in the injury rate for the forest industry on $1000 \mathrm{~m}^{3}$ of produced wood in the years 20002017 is illustrated in the graph (Fig. 3).

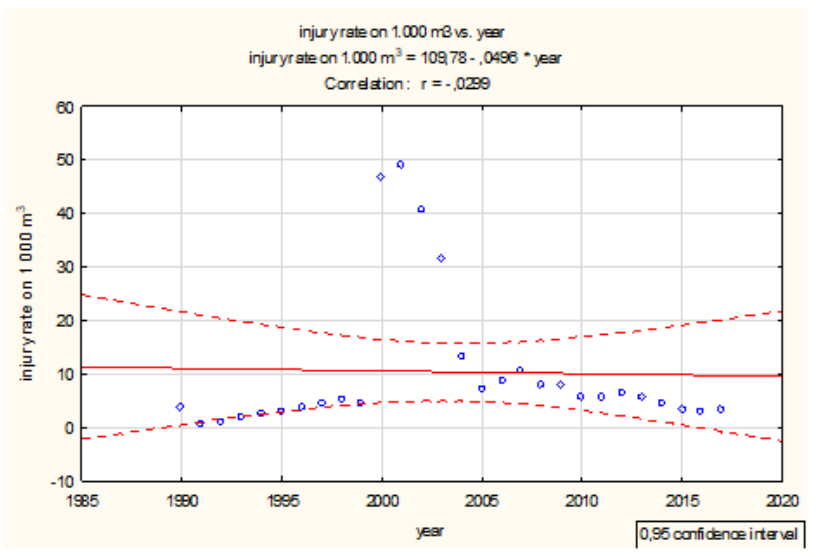

Figure 3: Trend in the injury rate on $1000 \mathrm{~m}^{3}$ in Slovakian state forests (years 2000-2017).

A simple one dimensional Poisson regression model can be used to analyse whether the trend in the injury rate is a function of one hypothetical variable - calendar year. The number of workplace injuries and the amount of produced wood in the Slovak forest industry in $1000 \mathrm{~m}^{3}$ were primary data in the first model. The effect of other prognostic variables was not taken into consideration. It is expressed using the formula:

$$
\ln \left(\lambda_{\text {year }}\right)=b_{0}+b_{1}(\text { year })
$$

where: $\lambda_{\text {year }}$ is an injury rate in each year.

Regression model (Fig. 4) described using formula 3 (hereinafter model (3)), means that ln (injury rate) should be dependent on the year $\left(b_{1}\right)$. Results of the regression analysis are mentioned in Table 2 .

Coefficients used in the model (3) were $b_{0}=-56.796$ and $\mathrm{b}_{1}=0.029$ with the standard error of s.e. $\left(b_{0}\right)=48.069$ and s.e. $\left(b_{1}\right)=0.023$. As it is shown in the model, the injury rate increases by 0.02 units per year after logarithmic transformation. Expected change in the number of injuries was $\exp (0.029)=1.0294$ from year to year. Therefore, the injury rate increases approximately by $2.94 \%[=100 \times(1$ $-1.0294) \%$ ] annually. An approximate $95 \%$ confidence interval for the parameter which is yearly changed is 0.029 $\pm 1.96(0.023)=(0.07408 ;-0.01608)$. Seeing that $b_{1}=0$, is in this interval, significant change in the primary observed injury rate per year is not expected. 
Table 1: Number of injuries according to part of body and days in week in State forestry enterprise (years 2000-2017

\begin{tabular}{cccccccc}
\hline Injured part of body & Monday & Tuesday & Wednesday & Thursday & Friday & Saturday & Sunday \\
\hline Head & 56 & 66 & 60 & 45 & 43 & 6 & 2 \\
Arm & 121 & 97 & 77 & 88 & 76 & 6 & 3 \\
Trunk & 49 & 48 & 49 & 46 & 41 & 2 & 3 \\
Whole body & 30 & 42 & 31 & 28 & 35 & 10 & 3 \\
Legs & 204 & 191 & 170 & 137 & 118 & 15 & 5 \\
Others and unidentified & 6 & 8 & 8 & 8 & 5 & 3 & 0 \\
Together & 466 & 452 & 395 & 352 & 318 & 42 & 16 \\
\hline
\end{tabular}

Table 2: Regression results with dependence variable (injury rate in forestry on produced $1000 \mathrm{~m}^{3}$

\begin{tabular}{|c|c|c|c|c|c|c|}
\hline \multicolumn{7}{|c|}{ Regression results with dependence variable : $C$ (injury Rate) $R=.23242478 R^{2}=.05402128$ Edited $R^{2}=$} \\
\hline \multicolumn{7}{|c|}{$.01763748 F(1,26)=1.4848 p$} \\
\hline $\mathrm{N}=\mathbf{2 8}$ & $\mathbf{b}^{*}$ & Standard error from $b^{*}$ & b & Standard error from $b$ & $t(26)$ & p-value \\
\hline Abs. term & & & -56.796 & 48.069 & 1.181 & 0.248 \\
\hline Year & 0.232 & 0.191 & 0.029 & 0.023 & 1.218 & 0.233 \\
\hline
\end{tabular}

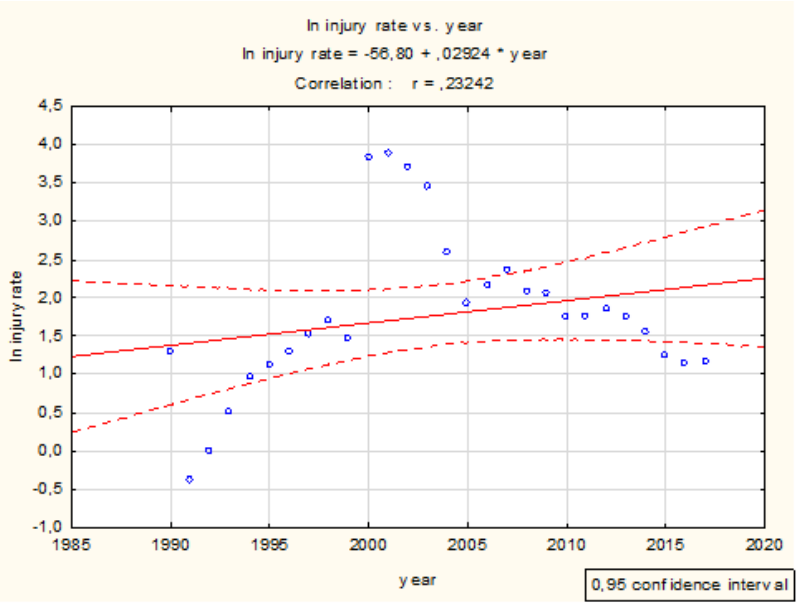

Figure 4: Trend in the injury rate in Slovak state forests (years 20002016) after calculation with model (3)

\section{Conclusion and discussion}

Nonsignificant increase in the injury rate over the years 2000-2017 was determined in the analysis of the injury rate in the Slovak state forests. Grzywinski et al. [24] analysed workplace accidents in Szczecinek (NW Poland) legally administered by the Regional Directorate of State Forests in the years 1990-2009. Following the analysis, the fact that the privatisation in the forestry industry did not affect the number of workplace accidents significantly, can be mentioned. In practise, measures for prevention and control can be inspired by the results of the analysis.
Benavides et al. [25] carried out the analysis in Spain and he found out that the injury rate of of seasonal workers (120.6 per 1000 employees in the year 2002) was higher than the injury rate of full-time workers (44.9 per $1000 \mathrm{em}$ ployees in the year 2002). It is supposed to be affected by quality professional training as well as work experience of full-time workers. In [26], a decrease in fatal injury rate in agriculture, game keeping and forestry in Arkhangelsk region from 43.9 per 1000 employees in the year 1996 to 20.8 per 1000 employees in the year 2007 is mentioned. In the work [27], authors compared the fatal injury rate in Australia and in the USA over the years 1989-1992 and in New Zealand over the years 1985-94. The average fatal injury rate in New Zealand was 4.9/100 000, in Australia 3.8/100 000 and in the USA 3.2/100 000. In the course of the years 1975 - 1984, the death rate of forest workers in New Zealand was 8.0 per 100,000 employees per year.

Suchomel [28] carried out the analysis of workplace accidents in the process of forest harvesting over the years 1984-1993. The position of individual phases in the process of harvesting, processing and transport was as follows: forest harvesting $-32 \%$, timber skidding $-29 \%$, works at skidway $-9 \%$, timber hauling $-8 \%$, works at conversion depot $-6 \%$, repairs and maintenance $-15 \%$ a controlling $-1 \%$. Following the overview, almost the same order of the phases as during the analysis period $2000-2017$ can be seen. Small differences result from subjective as well as objective factors. In the work [29] the analysis of Sweden is carried out. The results show that serious workplace accidents are very common in Sweden and the death rate of self-employed in forestry is $7 \%$ of the total number of 
workers killed in work related activities recorded by the employment office. Falling trees are the main cause of fatal or life-threatening injuries. Dangerous practises and procedures at work result in injuries more often than the working tools (e.g. portable chainsaw) used at the time of accidents. Therefore, quality trainings as well as skill improvement must be offered to line workers to equip them to deliver health and safety to the workplace.

When evaluating specific injured body parts in the analysis of workplace accidents, the authors [29] found out that a knee is the most commonly injured part of the body in the process of forest harvesting. The results of our analysis show that leg injuries occurred most often during harvesting as well (258). It means the injury rate of approximately $14 \%$ of all recorded injuries.

It is of utmost importance to create adequate conditions for carrying out warm and skilled work as well as for outsourced jobs. On the other hand, it is also necessary to require an adequate professional and physical level of workers. This can also be aided by a revised system of motivation and education of the workers [30].

From the point of view of the long-term changing anthropometric parameters of the adult population, it is also necessary to take into account the ergonomic parameters and the technological procedures of the performed work and the working environment [31-32].

Acknowledgments: The research described in this paper was financed jointly by APVV-16-0297 Updating of anthropometric database of Slovak population; VEGA Nr. 1/0031/18 Optimization of technological and work processes and risk assessment in the production of forest biomass for energy purposes.

\section{References}

[1] Hajdúchová, I., Giertliová, B., Šulek, R. 2017. Specifics of Forest Enterprises' Performance Measurement. Austrian Journal of Forest Science, 134, 23-40.

[2] Ďurišová, M., Kucharčíková, A., Tokarčíková, E. (2015). Assessment of higher education teaching outcomes (Quality of higher education). Procedia Social and Behavioral Sciences, 174, 2497 2502. DOI: $10.1016 /$ j.sbspro.2015.01.922.

[3] Kucharčíková, A., Mičiak, M. (2017). Human Capital Management in Transport Enterprise. MATEC Web of Conferences, 134, p. 00030. DOI: 10.1051/matecconf/201713400030.

[4] Němec, M., Krišták, L., Hockicko, P., Danihelová, Z., Velmovská, K. 2017. Application of Innovative P\&E Method at Technical Universities in Slovakia. Eurasia Journal of Mathematics Science and Technology Education, 13(6), 2329-2349. DOI: 10.12973/eurasia.2017.01228aa.
[5] Lorincová, S., Potkány, M. (2016). The proposal of innovation support in Small and Medium-sized Enterprises. Paper presented at International Conference on Engineering Science and Production Management (Zvolen, Slovakia), 2015, April 16-17, Zvolen:Production Management and Engineering Sciences, 157161.

[6] Stacho, Z., Potkany, M., Stachova, K., Marcinekova, K. (2016). The organizational culture as a support of innovation processes' management: a case study. International journal for quality research, 10(4), 769-783. DOI: 10.18421/IJQR10.04-08.

[7] Nemec, F., Lorincova, S., Hitka, M., Turinska, L. (2015). The Storage Area Market in the Particular Territory. Naše More, 62(3), 131-138. DOI: 10.17818/NM/2015/SI8.

[8] Eurostat. European Statistics on Accidents at Work (ESAW) Summary methodology, 2013; ISBN 978-92-79-28419-9.

[9] Edict Nr. 500/2006 The Ministry of Labour, Social Affairs and Family of the Slovak Republic. Pattern of record of registered work injury, 2006.

[10] Nussbaum, E.B. (2015). Contingency Tables The Chi-Square Test and Associated Effect Sizes. Routledge, Oxford, England, 2015; pp. 81-97.

[11] Richardson, J.T.E. (2011). The analysis of $2 \times 2$ contingency tables-Yet again. Stat. Med. 2011, 30(8), 890-890. DOI: https:/doi.org/10.1002/sim.4116.

[12] Šmelko, Š. (1998). Štatistické metódy v lesníctve [Statistical methods in Forestry]. Zvolen, TU Zvolen, Slovakia, 1998, 276 p. ISBN 80-228-0684-6

[13] Igaz, R., Kminiak, R., Krišták, L., Němec, M., Gergel', T. (2019). Methodology of Temperature Monitoring in the Process of CNC Machining of Solid Wood. Sustainability, 11

[14] Breslow, N.E., Day, N.E. (1980). Statistical Methods in Cancer Research Volume I - The analysis of case-control studies. International Agency For Research on Cancer, Lyon, France, 338 p., ISBN 978-9283201328.

[15] Berry, G. (1983). The analysis of mortality by the subject-years method. Biometrics, 39(1), 173-184. DOI: https://doi.org/10.2307/2530817.

[16] Frome, E.L. (1983). The analysis of rates using Poisson regression models. Biometrics, 39(3), 665-674. DOI: https:/doi.org/10.2307/2531094.

[17] Frome, E.L., Checkoway, H. (1985). Epidemiologic Programs for Computers and Calculators - Use of Poisson Regression-Models in Estimating Incidence Rates And Ratios. American Journal of Epidemiology, 121(2), 309-323. DOI: https:/doi.org/10.1093/oxfordjournals.aje.a114001.

[18] Whittemore, A.S. (1985). Analyzing cohort mortality data. American Statistics, 39(4), 437-441. DOI: https:/doi.org/ $10.2307 / 2683027$.

[19] Checkoway, H., Pearce, N.E., Crawford-Brown, D.J. (1989). Research methods in occupational epidemiology. Oxford University Press, New York, USA, ISBN-13: 9780195092424.

[20] Selvin, S. (1995). Practical biostatical methods. Duxbury Press, Belmont, California, USA, ISBN 0-534-23802-5. (1), 95.DOI: $10.3390 /$ su11010095.

[21] Anonymous. (2018) Green report. Ministry of Agriculture and Rural Development of the Slovak Republic, Bratislava, Slovakia, 65 p., ISBN 978 - 80 - 8093 - $255-8$.

[22] Dobson, A.J., Barnett, A.G. (2008). An Introduction to Generalized Linear Models. CRC Press, Taylor \& Francis Group, Boca Raton - Florida, USA, ISBN 978-1-58488-950-2. 
[23] McCullagh, P., Nelder, J.A. (1989). Generalized Linear Models, Second Edition. Chapman and Hall/CRC Press, Boca-Raton Florida, USA, ISBN 978-0-41231-760-6.

[24] Grzywinski, W., Sawa, L., Nowik, A., Nowicki, G. (2013). Structure of work accidents in the Regional Directorate of the State Forests in Szczecinek in the years 1990-2009. Sylwan, 157(6), 403-411.

[25] Benavides, F.G., Benach, J., Muntaner, C., Delclos, G.L., Catot, N., Amable, M. (2006). Associations between temporary employment and occupational injury: what are the mechanisms? Occupational and Environmental Medicine, 63(6), 416-421. DOI: https://doi.org/10.1136/oem.2005.022301.

[26] Varakina, Z.L., Vyazmin, A.M., Sannikov, A.L., Nygard, C.H., Grjibovski, A.M. (2010). Fatal occupational injuries in the Arkhangelsk region, Northwest Russia. Occupational Medicine-Oxford, 60(6), 470-475. DOI: https://doi.org/10.1093/occmed/kqq068.

[27] Feyer, A.M., Wiliamson, A.M., Stout, N., Driscoll, T., Usher, H., Langley, J.D. (2001). Comparison of work related fatal injuries in the United States, Australia, and New Zealand: method and overall findings. Injury Prevention, 7, 22-28.
[28] Suchomel, J. (1999). Analýza vybraných kritérií a metód pre modelovanie a optimalizáciu tažbového procesu [Analysis of selected criteria and methods for modelling and optimization of harvesting process]. Habilitation work, Technical University in Zvolen, pp. 148. Zvolen.

[29] Lindroos, 0., Burstrom, L. (2010). Accident rates and types among self-employed private forest owners. Accident Analysis and Prevention, 42(6), 1729-1735. DOI: https://doi.org/10.1016/j.aap.2010.04.013.

[30] Hitka, M., Joščák, P., Langová, N., Krišták, L., Blašková, S. (2018). Load-carrying Capacity and the Size of Chair Joints Determined for Users with a Higher Body Weight. Bioresources, 13(3), 6428-6443.

[31] Hitka, M., Vetráková, M., Balážová, Ž., Danihelová, Z. 2015. Corporate Culture as a Tool for Competitiveness Improvement. Procedia Economics and Finance, 34, 27-34. DOI: 10.1016/S22125671(15)01597-X.

[32] Réh, R., Krišták, L., Hitka, M., Langová, N., Joščák, P., Čambál, M. (2019). Analysis to Improve the Strength of Beds Due to the Excess Weight of Users in Slovakia. Sustainability, 11(3), 624. DOI: $10.3390 /$ su11030624. 